\title{
Landslide susceptibility on selected slopes in Dzanani, Limpopo Province, South Africa
}

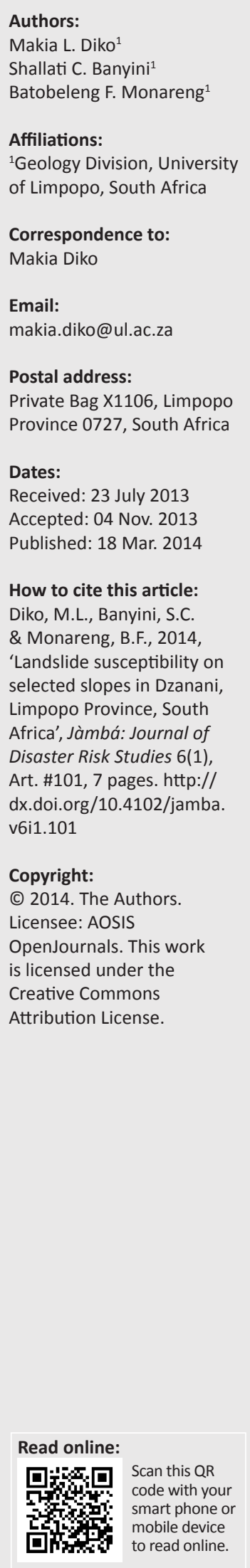

Inherent soil properties and anthropogenic activities on slope faces are considered potential recipes for landslide occurrence. The objectives of this study were to physically characterise unconsolidated soils and identify on-going anthropogenic activities on selected slopes in Dzanani in order to appraise their role as contributory factors in enhancing landslide susceptibility. Methods employed for this study comprised mapping, description of soil profile, identification of anthropogenic activities, as well as experimental determination of soil colour, particle size distribution and Atterberg limits. Geologically, the study area comprised rocks of the Fundudzi, Sibasa and Tshifhefhe Formations, ascribed to the Soutpansberg Group. Digging of foundations for construction purposes and subsistence agriculture were identified as the main anthropogenic activities. The soils were predominantly reddish-yellow in colour, texturally variable (silty clay - clayey - silty clay loam and clay loam) and of medium plasticity. Compared to soils from other parts of the world developed on volcanic cones or associated with a landslide event, those from Dzanani were qualified as generally inactive and not prone to landslides. Although the physical attributes suggested the soils were not at a critical state, on-going anthropogenic activities may enhance deep weathering and ultimately alter current soil physical characteristics to a critical state.

\section{Introduction}

Landslide risk is the potential for adverse consequences, loss, harm, or detriment to human population and property as a result of landslide (Lee \& Zones 2004). It can be viewed as a combination of the probability of occurrence (susceptibility) and the consequences resulting from landslides. This article reports on the risks of landslide susceptibility associated with soils developed on volcanic rocks in Dzanani, Limpopo Province, South Africa. Over the past decade, slopes in this area have attracted an increasing number of human habitants. Most of the houses on these hill slopes appear to be oblivious to possible underlying threats from mass movements (Banyini 2012). In conjunction with inherent soil properties, the anthropogenic activities on these slopes are considered potential recipes for landslide occurrence.

\section{Background}

The effects of landslides on human life, property and the economy of many nations have been extensively documented (Anbalagan 1992; Ercanoglu \& Gokceoglu 2002; Ercanoglu, Gokceoglu \& Van Aseh 2004; Micheal-Leiba et al. 2003); however, according to Ercanoglu et al. (2004), the economic loses and casualties resulting from landslides in many countries are greater than commonly recognised. This situation is even more deplorable in developing countries, which are comparatively less equipped technically and financially to deal with natural hazards (Diko 2012; Ngole, Ekosse \& Ayonghe 2007). In South Africa, despite significant strides made towards consolidating data on geohazards in the country, very few studies on mass movements have been documented (Singh et al. 2008). Examples include the Mount Curie debris avalanche in Kokstad, KwaZulu-Natal, the Lake Fundudzi Paleo-landslide in Limpopo Province and the UkhahlambaDrankensburg foot slope landslides in KwaZulu-Natal (Singh et al. 2008). In addition to these slides, a number of slumps within dolomitic host rocks have been reported in isolated areas in Johannesburg (Banyini 2012). In Limpopo Province, with the exception of the Lake Fundudzi landslide, no other study has been documented.

By definition, landslides are a form of mass movement in which bedrock, rock debris or soil move down a slope under the influence of gravity (Plummer, Geary \& Carlson 1999). Landslides within the anthropic environment are often the primary expression of interactions between the socalled contributory and triggering factors (Ayonghe et al. 2002; Ayonghe et al. 2004; Ercanoglu \& Gokceoglu 2002; Ercanoglu et al. 2004; Guzzetti, Cardinali \& Reichenbach 1999; Pachauri \& Pant 1992; Pachauri, Gupta \& Chandler 1998; Van Western et al. 1997; Varnes 1984; Zezere, Ferrira \& Rodrigue 1999). Depending on their inherent characteristics at any given time, contributory factors 
(e.g. geology, soil physical and mineralogical properties, geomorphology, land-use and hydrologic conditions within the vicinity of the slope) can serve as driving or resisting forces acting on a slope (Anbalagan 1992).

With respect to slides on slope faces, Yalcin (2007) argued that weathering is by far the most important contributory factor. Weathering is the first step in a series of geomorphic and bio-geochemical alteration processes affecting rocks and minerals at or near the Earth's surface. This often results in the formation of soils with variable textural (sand, silt and clay-sized fractions) and mineralogical compositions (clay and non-clay minerals) (Summa et al. 2010). Soil physical and mineralogical properties are two attributes that tend to influence the soils geotechnical characteristics such as consistency limits, activity, swelling potential, porosity, permeability, shearing and stress resistance. The presence of clays (used here - in both as particle size and mineral term) in soils, for example, has been associated with landslide occurrence (Ekosse et al. 2005; Fall \& Sarr 2007; Ngole et al. 2007; Yalcin 2007). According to these authors, studies on the physico-chemistry, mineralogy and geotechnical properties of soil clays provides useful insight into the dynamics of hill slopes especially in landslide prone areas.

Triggering factors (rainfall, earthquake and anthropogenic activity), on the other hand, are responsible for imparting the extra energy required to overcome inertia and set the slope in motion (Ayonghe et al. 2004; Ercanoglu \& Gokceoglu 2002; Ercanoglu et al. 2004; Guzzetti et al. 1999; Zezere et al. 1999). Whilst rainfall and earthquakes are events beyond human control, anthropogenic activities represent the totality of human interaction with the anthropic environment. For example, agricultural activity on slope faces destroys soil structure, increases permeability and porosity and reduces overall shearing strength of the soil. According to Knapen et al. (2006), deforestation and vegetation loss may reduce up to $90 \%$ of slope stability. Poorly planned forest clearing may increase rates of surface-water run-off or ground-water infiltration. Inefficient irrigation or sewage effluent disposal practices may result in increased ground-water pressures and reduction in stability of rock and sediment (Knapen et al. 2006). Excessive runoff can also cause soil erosion and increased risk of landslides. Cutting of slope faces for foundation purposes or excavations at the base of a slope without an effective drainage system, retaining wall or some form of toe protection can immediately or eventually result in sliding (Yalcin 2007).

Given that landslide risk assessment has not been conducted in Dzanani area, the objectives of this study are to, (1) physically characterise unconsolidated soils obtained at variable depths from selected slope face, (2) ascertain their role as contributory factors in enhancing landslide occurrence and (3) investigate the type(s) and impact of anthropogenic activities on landslide susceptibility in the area. It is anticipated that findings from this study may, (1) create awareness on the potential risks of landslides on hill slopes (within this community and similar areas in South Africa or beyond), (2) challenge local officials or government to implement strict regulations for building on slope faces and (3) serve as a basis for initiating capacitybuilding programmes on landslide hazard management in communities prone to landslides.

\section{Research method and design Study area}

Dzanani is approximately $30 \mathrm{~km}\left(23^{\circ} 00^{\prime} \mathrm{N}-23^{\circ} 05^{\prime} \mathrm{N}\right.$ and $\left.30^{\circ} 17^{\prime} \mathrm{E}-30^{\circ} 25^{\prime} \mathrm{E}\right)$ from Thohoyandou, Limpopo Province (Figure 1). The area has a mountainous relief with elevations of up to 1100 m.a.s.l. (Banyini 2012). Climate is fairly humid, with a mean annual rainfall ranging from $755 \mathrm{~mm}$ to $798 \mathrm{~mm}$. The mean maximum daily temperature over the area ranges between $30{ }^{\circ} \mathrm{C}$ and $34{ }^{\circ} \mathrm{C}$ during summer and between $22{ }^{\circ} \mathrm{C}$ and $26^{\circ} \mathrm{C}$ in winter. Mean minimum daily temperature

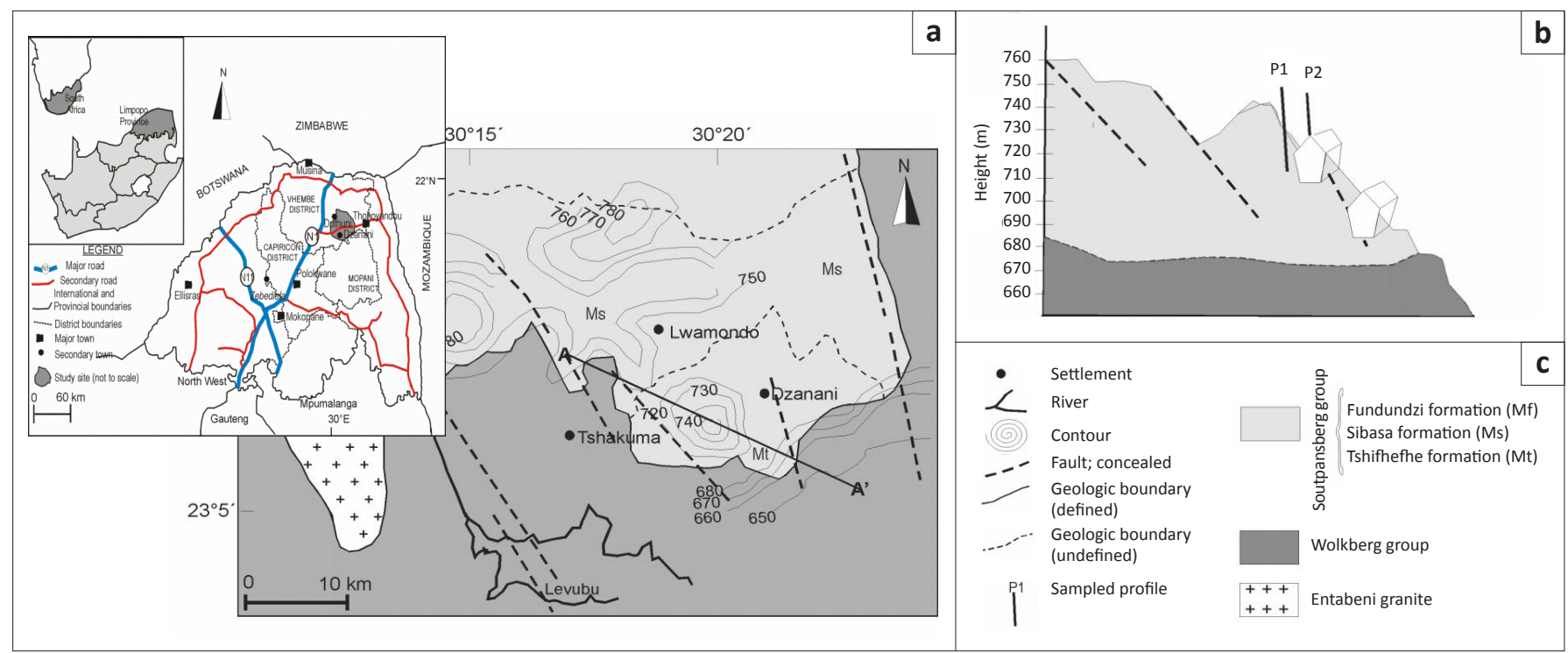

Source: Maps produced by authors

FIGURE 1: (a) Location of study area and regional geology, with (b) cross-section of selected slope face $\left(A-A^{\prime}\right)$ and (c) the legend of the figure. 
ranges from $18{ }^{\circ} \mathrm{C}$ to $22^{\circ} \mathrm{C}$ in summer and from $5^{\circ} \mathrm{C}$ to $10{ }^{\circ} \mathrm{C}$ in winter (Banyini 2012).

\section{Design}

This study employed both field and laboratory analyses. Fieldwork involved geologic mapping, description of slope aspect, soil profiles and identification of anthropogenic activities on studied slopes. For laboratory analysis, nine disturbed soil samples were collected at variable depths from a representative soil profile and subjected to colour, particle size distribution (PSD) and Atterberg limits tests.

\section{Procedure}

Colour was determined using the Munsell soil colour book (Diko et al. 2012). Samples were aerated for $24 \mathrm{~h}$. Using a spatula, soil aggregates were mounted on white cardboard sheets. The hue, value, chroma and colour of the mounted samples were obtained by visually comparing them to those recorded in the Munsell soil colour book.

The PSD was determined using the sieve and hydrometer analysis (Diko et al. 2011). The samples were aerated for $2 \mathrm{~h}$ and sieved through the $2 \mathrm{~mm}, 1 \mathrm{~mm}, 500 \mu \mathrm{m}, 250 \mu \mathrm{m}$, $125 \mu \mathrm{m}$ and $63 \mu \mathrm{m}$ sieves using an electric shaker. The retained fraction on each sieve was recuperated and weighed. For the hydrometer analysis, $40 \mathrm{~g}$ of $<63 \mu \mathrm{m}$ fraction was placed in a shaker bottle, filled with $30 \mathrm{~mL}$ of dispersant (sodium hexametaphosphate) and $200 \mathrm{~mL}$ of deionised water. The content was mixed on a horizontal shaker for $16 \mathrm{~h}$, emptied into a $1 \mathrm{~L}$ volumetric flask and topped to the $1 \mathrm{~L}$ mark with deionised water. A second volumetric flask (control) containing $30 \mathrm{~mL}$ of dispersant was equally filled with deionised water to the $1 \mathrm{~L}$ mark. The first flask (experiment) was again agitated manually and allowed to stand for about $30 \mathrm{~s}$, followed by hydrometer measurements after $30 \mathrm{~s}$, $1 \mathrm{~min}, 2 \mathrm{~min}, 10 \mathrm{~min}, 20 \mathrm{~min}, 40 \mathrm{~min}, 80 \mathrm{~min}, 120 \mathrm{~min}$ and $1440 \mathrm{~min}$. The hydrometer was placed $20 \mathrm{~s}$ before taking a reading in order to allow the hydrometer to stabilise. After each measurement, the temperature of the soil suspension was taken. Hydrometer and temperature measurements were equally taken for the control as well. Calculation of the particle size was determined based on Stokes law of sedimentation of individual spherical particles settling under the influence of gravity. The diameter $(D)$ of those particles that would have settled over a given distance $(L)$ at time $(T)$ was obtained from the following equation:

$D=\mathrm{K}(L / T)^{0.5}$

[Eqn 1]

Where $\mathrm{K}$ is constant depending on the temperature of the suspension and the specific gravity of the soil particles and $L$ is the effective depth of each hydrometer reading.

Atterberg limits were performed on the $<63 \mu \mathrm{m}$ fraction samples using the Cassagrande apparatus (Casagrande 1948). The following tests were conducted: liquid limit (LL), plastic limit (PL), plasticity index (PI) and coefficient of activity (CA). For LL determination, $40 \mathrm{~g}$ of previously prepared fine mortar was spread in a cup (maximum thickness =
$1 \mathrm{~cm}$ ) and divided by a standard axial groove. Liquid limit was expressed as a percentage by weight of the mortar after drying in an oven at $105^{\circ} \mathrm{C}$, at which the groove closes over a length of $1 \mathrm{~cm}$ under the influence of 25 blows. The blows were produced by allowing the cup to drop from a height of $1 \mathrm{~cm}$ onto a hard surface. In order to determine the PL, $10 \mathrm{~g}$ of the fine mortar was used. Using the palm, the mortar was rolled on a flat surface until the tread of fine mortar broke into sections of between $1 \mathrm{~cm}$ and $2 \mathrm{~cm}$ long, after being reduced to a diameter of $3 \mathrm{~mm}$. The PL was expressed as a percentage by weight after oven drying at $105{ }^{\circ} \mathrm{C}$. Plasticity index was obtained from the arithmetic difference between LL and PL, whereas CA was calculated from the following expression:

$\mathrm{CA}=\mathrm{PI} /$ clay $w \mathrm{t} \%$

[Eqn 2]

Where $\mathrm{wt} \%$ is the weight of clay expressed as a percentage.

\section{Results}

\section{Field observations Slope aspect}

The studied slope was divided into three segments: upslope, mid-slope and down-slope (Figure 2). The up-slope, located at $23^{\circ} 03^{\prime} 37^{\prime \prime} \mathrm{N} 30^{\circ} 20^{\prime} 10^{\prime \prime} \mathrm{E}$ was about $780 \mathrm{~m}$ high with a gradient of $34^{\circ}$. At mid-slope $\left(23^{\circ} 03^{\prime} 46^{\prime \prime} \mathrm{N} 30^{\circ} 20^{\prime} 4^{\prime \prime} \mathrm{E}\right)$, an elevation of 669 m.a.s.l. with an average gradient of $40^{\circ}$ was measured. Further down-slope $\left(23^{\circ} 03^{\prime} 51^{\prime \prime} \mathrm{N} 30^{\circ} 20^{\prime} 16^{\prime \prime} \mathrm{E}\right)$, the relief was gentle with gradients between $12^{\circ}$ and $15^{\circ}$ and an altitude of 676 m.a.s.l. According to Dai and Lee (2002) over $60 \%-75 \%$ of landslide occurrences are on slopes with gradients $>30^{\circ}$ and $\leq 40^{\circ}$. Up-slope and mid-slope gradients in the study area were greater than the angle of repose $\left(30^{\circ}\right)$ suggested for stable slopes. Based on slope aspect the area was considered landslide prone.

\section{Regional geology and description of soil profile}

The geology of the Dzanani area is dominated by rocks of the Soutpansberg Group, which consists of a volcanicsedimentary succession that comprises seven different

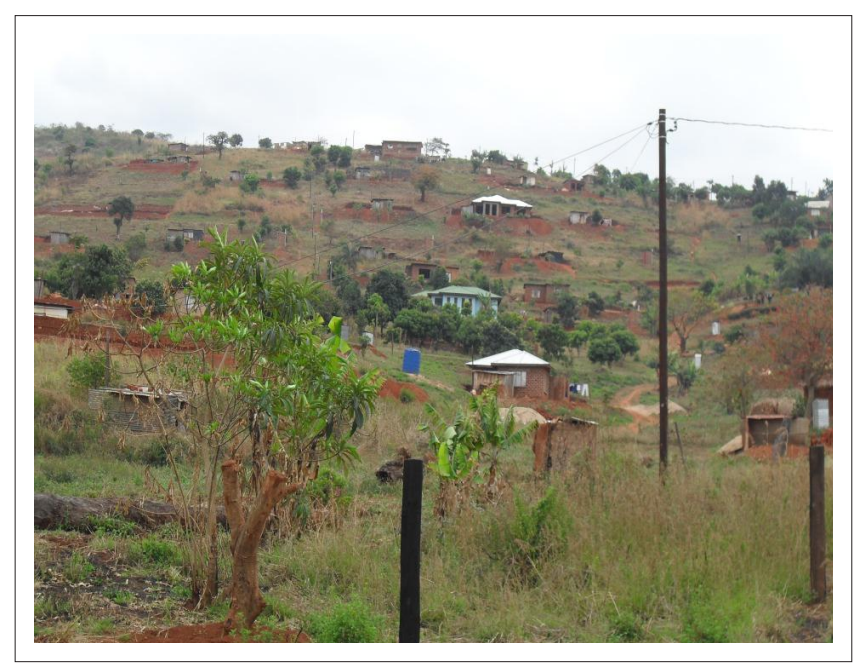

Source: Photo taken by authors

FIGURE 2: View of hill slope at Dzanani. 
formations, namely: Tsifhefhe, Sibasa, Fundudzi, Wyllie's Poort, Stayt, Mabaligwe and Nzhelele Formations. Most of the Soutpansberg strata dip at $30^{\circ}$ in the north-north-east direction, truncated by continuous structures forming faultbounded elongate blocks (Barker 1979). Within the vicinity of Dzanani, the geology is characterised by Fundudzi, Sibasa and Tshifhefhe Formations (Banyini 2012).

The basal discontinuous Tshifhefhe Formation was only a few metres thick and made up of strongly epidotised clastic sediments, including shale, greywacke and conglomerate. The succeeding Sibasa Formation was dominantly volcanic, with rare discontinuous intercalations of clastic sediments. The volcanics comprised sub-aerially extruded basalts and minor pyroclastic materials. The overlying Fundudzi Formation was developed only in the north, and wedged out towards the west (Figure 1). It consisted mainly of arenaceous and argillaceous sediments with a few thin pyroclastic horizons. Towards the south, the Souptpansberg rocks were covered by sediments of the Wolkberg Group and, in the south-east, by Entabeni granites. The orientations of the incised valleys in the study area were consistent with those of the regional tectonics of the Soutpansberg Group (north-north-east), suggesting the presence of concealed faults underneath.

The representative profile (exposed at slope face) comprised three distinct horizons: topsoil, mid-horizon and lower horizon (Figure 3). The topsoil measured $0.50 \mathrm{~m}$ thick and appeared dark in colour, probably as a result of its organic matter content. The mid horizon was the thickest, averaging $1.75 \mathrm{~m}$ with basaltic fragments embedded within a finegrained groundmass. This horizon was dark red to reddish in colour, suggesting the presence of hematite $\left(\alpha-\mathrm{Fe}_{2} \mathrm{O}_{3}\right)$. The third horizon was slightly over $0.75 \mathrm{~m}$ thick, with a yellowish colour, inferring goethite $(\alpha-\mathrm{FeOOH})$ predominance. The latter equally displayed a more sticky consistency compared to the overlying horizons, suggesting relative clay enrichment with significant potentials for sliding of the overlying horizon.

\section{Anthropogenic activities}

Human intervention on the slopes was observed in the form of digging of foundations for construction purposes (Figure 4a) and subsistence agriculture, evidenced through slash-and-burn techniques adopted by some hill-slope dwellers (Figure 4b). Most of the foundations, especially those next to inhabited houses, did not have retaining walls, drainage systems or any form of protection (Figure $4 a$ ).

\section{Soil physical properties}

\section{Soil colour}

Soil colour ranged from bright reddish-brown (S1), through reddish-brown (S2, S3), reddish-yellow (S4-S6) to brownishyellow (S7-S9) with profile depth (Table 1). Soil colour suggested enrichment of goethite over hematite and a more prevalent reducing environment with an increase in reduction reactions with depth $\left(\mathrm{Fe}^{3+} \rightarrow \mathrm{Fe}^{2+}\right)$.

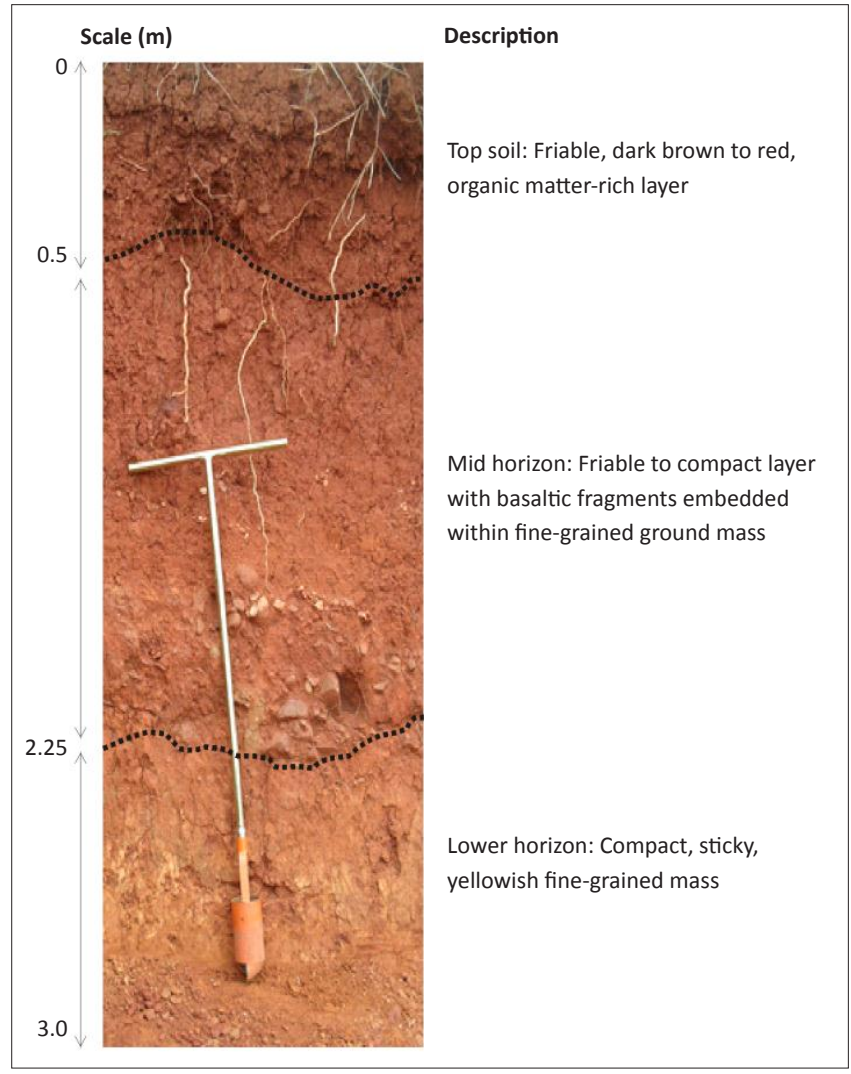

Source: Primary data generated for this study; photo taken by authors

FIGURE 3: Soil profile exposed at cut slope face.
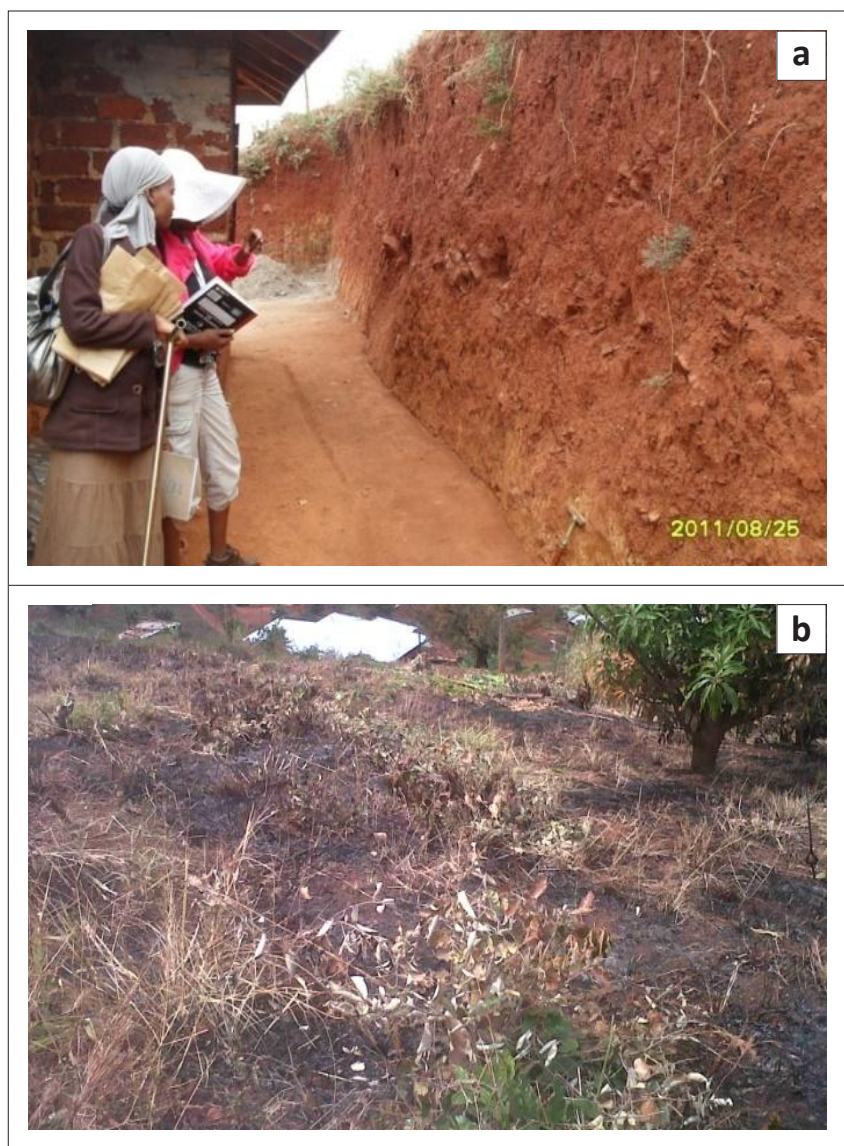

Source: Photos taken by authors

FIGURE 4: Anthropogenic activities on slopes at Dzanani include, (a) digging of foundations and (b) slash-and-burn farming. 
TABLE 1: Soil physical properties.

\begin{tabular}{|c|c|c|c|c|c|c|c|c|c|c|c|}
\hline \multirow[t]{2}{*}{ Sample } & \multirow[t]{2}{*}{ Hue } & \multirow[t]{2}{*}{ Value } & \multirow[t]{2}{*}{ Chroma } & \multirow[t]{2}{*}{ Colour } & \multirow[t]{2}{*}{ Sand $\%$ (> $63 \mu \mathrm{m})$} & \multirow[t]{2}{*}{ Silt $\%(63 \mu \mathrm{m}-2 \mu \mathrm{m})$} & \multirow[t]{2}{*}{ Clay $\%(<2 \mu \mathrm{m})$} & \multicolumn{4}{|c|}{ Atterberg limits } \\
\hline & & & & & & & & LL & PL & PI & CA \\
\hline S1 & $2.5 Y R$ & 5 & 8 & Bright reddish-brown & 16 & 54 & 30 & 46.20 & 35.5 & 10.70 & 0.36 \\
\hline S2 & $2.5 Y R$ & 4 & 8 & Reddish-brown & 12 & 50 & 38 & 55.06 & 50.0 & 5.06 & 0.13 \\
\hline S3 & $2.5 Y R$ & 4 & 8 & Reddish-brown & 30 & 42 & 28 & 41.90 & 40.0 & 1.90 & 0.07 \\
\hline S4 & $5 Y R$ & 6 & 8 & Reddish-yellow & 14 & 52 & 34 & 40.30 & 47.1 & nd & nd \\
\hline S5 & $5 Y R$ & 6 & 8 & Reddish-yellow & 10 & 48 & 42 & 50.70 & 39.5 & 11.20 & 0.27 \\
\hline S6 & $5 Y R$ & 6 & 8 & Reddish-yellow & 24 & 46 & 30 & 41.60 & 29.0 & 12.60 & 0.42 \\
\hline S7 & 10YR & 6 & 6 & Brownish-yellow & 14 & 44 & 42 & 53.50 & 44.7 & 12.60 & 0.21 \\
\hline S8 & $10 Y R$ & 6 & 6 & Brownish-yellow & 18 & 34 & 48 & 37.70 & 34.7 & 8.80 & 0.07 \\
\hline S9 & 10YR & 6 & 6 & Brownish-yellow & 12 & 42 & 46 & 49.50 & 45.5 & 4.00 & 0.08 \\
\hline
\end{tabular}

YR, yellow-red; LL, liquid limit; PL, plastic limit; PI, plasticity index; CA, coefficient of activity; nd, not determined.

\section{Particle size distribution}

From PSD, the samples were significantly richer in silt and clay contents (Table 1). Clay content of the soil varied between $28 \%$ and $48 \%$, silt content between $34 \%$ and $54 \%$, whereas sand content ranged from $10 \%$ to $30 \%$. Texturally, the samples were classified as silty clay (S5, S7 and S9), clayey (S8), silty clay loam (S3 and S6) and clay loam (S1, S2 and S4) (Figure 5). The PSD of the samples were plotted on a landslide susceptibility ternary diagram (Figure 6) proposed by Talerico, Schuring and Khera (2004). In comparison with other soils developed on volcanic cones from Cameroon (Mbonjo landslide) (Diko et al. 2012) and those obtained from the Sparta slide, New Jerseym as well as nine other landslides in San Francisco, California (Talerico et al. 2004), samples from Dzanani plotted away from the projected failure zones. Based on PSD the unconsolidated soils from Dzanani were not considered as being at a critical state.

\section{Atterberg limits}

The measured LL, PL, PI and CA of the studied soil samples were variable. The LL ranged from $37.70 \%$ to $55.06 \%$, PL from $29.00 \%$ to $50.00 \%$, PI ranged from 4.0 to 12.6 , whereas CA ranged from 0.07 to 0.42 (Table 1 ). In order to gain insights into soil behaviour in response to water content and the subsequent implications for landslide occurrence, Atterberg limits of the studied samples were plotted on a plasticity diagram (Mugagga et al. 2011). Plasticity of the samples ranged from medium to high, with about $80 \%$ plotting within the medium plasticity field and $20 \%$ within the high plasticity field (Figure 7).

Swelling potential of Dzanani soils was further assessed based on their CA. By comparing soil PI and amount of claysized fraction $(<2 \mu \mathrm{m})$ present, the activity or expansivity of the soil was quantitatively described (Fall \& Sarr 2007). With the exception of two samples (S6 and S1) which plotted close to the 'inactive-normal' boundary line on the activity diagram (Figure 8), the rest of the samples were classified as inactive.

\section{Discussion}

\section{Anthropogenic activity and soil physical property effects on Dzanani landslide risk}

From the observed anthropogenic activities, in the event of a slide, houses next to displaced regolith would be hard

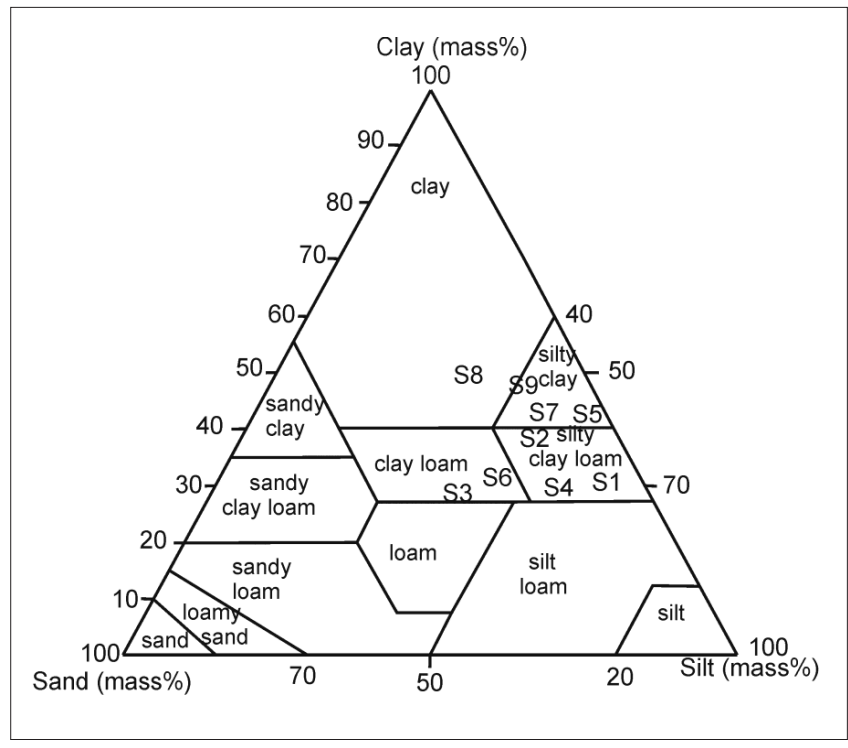

Source: Primary data generated for this study S1-S9, soil samples.

FIGURE 5: Textural classification of unconsolidated sediments from Dzanani.

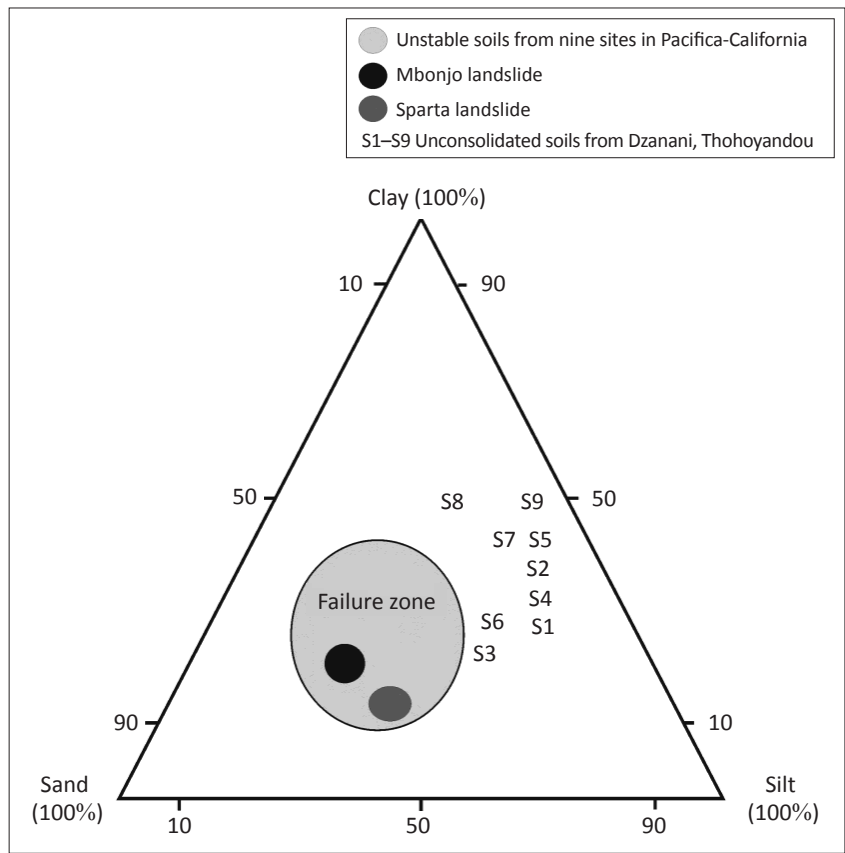

Source: Adapted from Talerico, J., Schuring, J.R. \& Khera, R.P., 2004, 'A landslide in glacial soils of New Jersey', paper presented at the 5th International Conference on Case Histories in Geotechnical Engineering, New York, 13-17 April

FIGURE 6: Location of Dzanani unconsolidated soil samples on landslide susceptibility ternary diagram. 
hit. On the contrary, where slope protective measures are in place, the velocity and magnitude of regolith displacement and consequent risk on human life and property may be significantly reduced (Ayonghe et al. 2004). Although agriculture is being practiced by only a few individuals in Dzanani, their activities may present significant risks for the entire hill-slope community. Agricultural activities on hill slopes have been shown to loosen soil structure, increase porosity, permeability and run-off (through irrigation), enhance deep weathering and reduce overall shearing strength of soils (Anbalagan 1992; Ercanoglu \& Gokceoglu 2002; Knapen et al. 2006). The above effects help build the

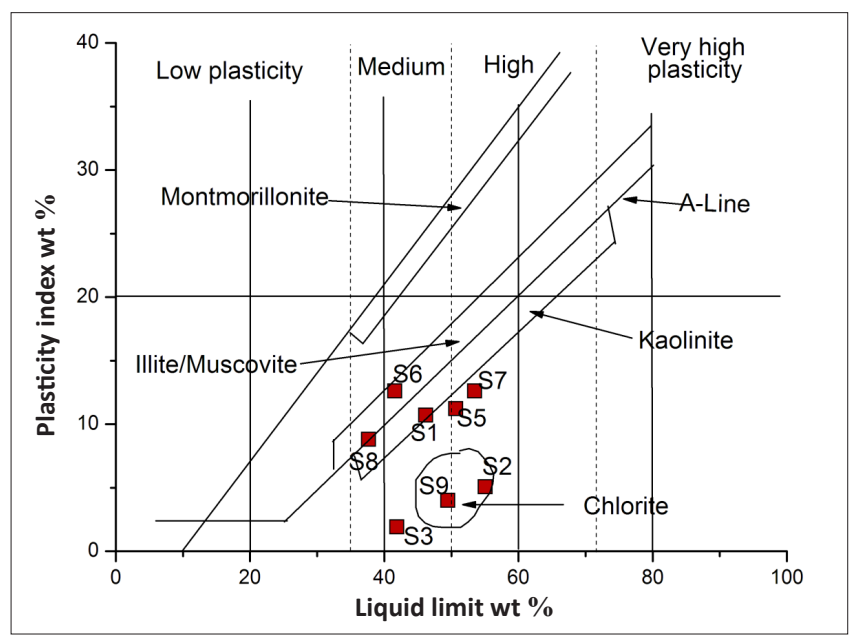

Source: Primary data generated for this study

wt, weight; S1-S9, soil samples.

FIGURE 7: Soil plasticity with inferred clay mineralogy.

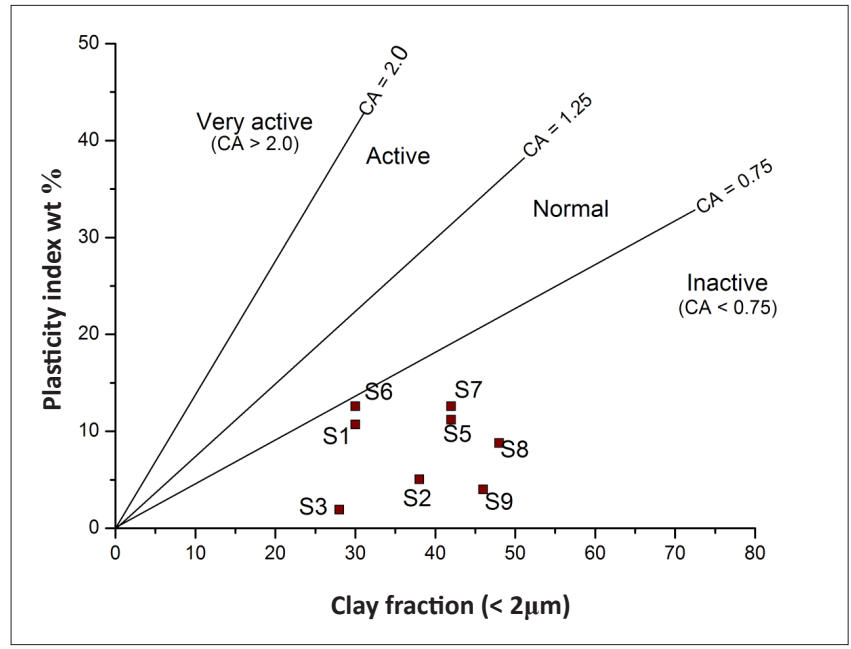

Source: Primary data generated for this study

CA, coefficient of activity; wt, weight; S1-S9, soil samples.

FIGURE 8: Activity diagram for soil samples from Dzanani. slope to a critically unstable state, rendering it highly susceptible to landslides.

Atterberg limits are a set of index tests performed on finegrained soils to determine the relative activity of the soils and their relationship to moisture content. Depending on how much moisture the soil can retain, it would exist in any of the four states: solid, semi-solid, plastic or liquid. For each state, the consistency and behaviour of the material is different and so is its load-bearing capacity and overall stability. Plasticity defines the ability a soil to undergo unrecoverable deformation at constant volume without cracking or crumbling (Yalcin 2007). The degree of swelling is a function of PSD, amount and type of clay minerals present in the soil (Mugagga, Kakembo \& Buyinza 2011).

The observed plasticities of soils from the study area were consistent with inferred clay mineralogy (Figure 7). From the diagram (Figure 7), about $66 \%$ of the samples were considered predominantly kaolinitic, whereas just over $40 \%$ were ascribed to the chlorite domain. Based on inherent physical and chemical properties of these clay minerals (Table 2), the swelling potential of the soils was described as almost none to none (eds. Parker \& Rae 1998). This therefore suggests that the soil from Dzanani can be qualified as noncritical and thus not landslide prone.

However, given that weathering on these slopes is a continuous process (although proceeding at variable rates and intensity), coupled with on-going anthropogenic activities, the probability of the soils to grade into active status over time cannot be ruled out.

\section{Limitations of the study}

The current study focused mainly on anthropogenic controls and physical properties of the soils developed on slopes. Furthermore, only one selected slope face was studied. Thus, results presented herein, although informative, may not be generalisable for all slopes in the entire area. On the basis of these shortcomings the following recommendations are made:

- In order to complement current findings, studies on geotechnical, mineralogical and geochemical characteristics of the soils in relation to landslide susceptibility should be conducted.

- Quantitative landslide risk assessment in the entire area should be carried out.

\section{Conclusion}

The objectives of this study were to physically characterise unconsolidated soils developed on hill slopes from Dzanani

TABLE 2: Summary of clay mineral properties.

\begin{tabular}{|c|c|c|c|c|}
\hline Secondary mineral & Type & Interlayer condition and bonding & CEC (cmol/kg) & Swelling potential \\
\hline Kaolinite & 1:1 (non-expanding) & Lack of interlayer surface, strong bonding & $3-15$ & Almost none \\
\hline Montmorillonite & 2:1 (expanding) & Very weak bonding, great expansion & $80-150$ & High \\
\hline Vermiculite & 2:1 (expanding) & Weak bonding, great expansion & $100-150$ & High \\
\hline Hydrous mica & 2:1 (non-expanding) & Partial loss of $\mathrm{K}$, strong bonding & $10-40$ & Low \\
\hline Chlorite & 2:1:1 (non-expanding) & Moderate to strong bonding, non-expanding & $10-40$ & None \\
\hline
\end{tabular}

$\mathrm{K}$, potassium; CEC, cation exchange capacity. 
and to identify on-going anthropogenic activities in order to appraise their role as contributory factors in enhancing landslide susceptibility. Both field (mapping, description of soil profiles and identification of anthropogenic activities) and laboratory techniques (colour, PSD and Atterberg limits) were employed.

Geologically, the study area comprised rocks of the Fundudzi, Sibasa and Tshifhefhe Formations, ascribed to the Soutpansberg Group - a volcano-sedimentary succession. The representative profile comprised three distinct horizons: an underlying yellowish compact, comparatively stickier lower horizon, overlain by a mid-horizon characterised by basaltic fragments embedded within a fine-grained groundmass, capped by an organic, matter-rich topsoil. Subsistence agriculture and digging of foundations for construction purposes were identified as the main anthropogenic activities. From physical characterisation, the samples were predominantly reddish-yellow in colour, texturally variable (silty clay - clayey - silty clay loam and clay loam), of medium plasticity and generally inactive. Compared to materials from other parts of the world developed on volcanic cones or associated with a landslide event, soils from Dzanani were qualified as not landslide prone.

Although physical attributes of studied samples suggest the soils are not at a critical state, over time, the on-going anthropogenic activities may enhance deep weathering on slopes and ultimately alter current soil physical characteristics (change to critical state), with a consequent increase in landslide susceptibility. Given that only physical properties were addressed in this study, research on geotechnical, mineralogical and geochemical aspects are recommended in order to have an in-depth appraisal of potential landslide risk on the slopes in Dzanani.

\section{Acknowledgements}

The authors are grateful to the hill-slope residents for their cooperation during fieldwork. Soil physical properties were determined at the Soil Science and Basic Soil Mechanics Laboratories of the University of Limpopo.

\section{Competing interests}

The authors declare that they have no financial or personal relationships which may have inappropriately influenced them in writing this article.

\section{Authors' contributions}

M.L.D. (University of Limpopo) conceived the project, overviewed fieldwork and experimental design and prepared the manuscript, S.C.B. (University of Limpopo) was responsible for the literature survey, experimental design and fieldwork and B.F.M. (University of Limpopo) assisted with fieldwork and experimental design.

\section{References}

Anbalagan, R., 1992, 'Landslide hazard evaluation and zonation mapping in mountainous terrain', Engineering Geology 32, 267-277. http://dx.doi. org/10.1016/0013-7952(92)90053-2
Ayonghe, S.N., Ntasin, E., Samalang, P. \& Fantong, W., 2002, 'Hydrologically, seismically and tectonically triggered landslides along the Cameroon Volcanic Line, Cameroon', Geoscience Review 9(4), 325-335.

Ayonghe, S.N., Ntasin, E., Samalang, P. \& Suh, C.E., 2004, 'The June 27, 2001 landslide on volcanic cones in Limbe, Mount Cameroon, West Africa', Journal of African Earth Science 39, 435-439. http://dx.doi.org/10.1016/j.jafrearsci.2004.07.022

Banyini, S.C., 2012, 'Physico-chemistry of unconsolidated soils from selected cones in Thohoyandou, Limpopo Province: Implications for future landslide risk', Honours research project, Geology Division, University of Limpopo.

Barker, O.B., 1979, 'A contribution to the geology of the Soutpansberg Group, Waterberg Supergroup, Northern Transvaal', MSc thesis, University of Witwatersrand.

Casagrande, A., 1948, 'Plasticity chart for the classification of cohesive soils', Transactions of the American Society of Civil Engineering 113, 901.

Dai, F.C. \& Lee, C.F., 2002, 'Landslide characteristics and slope instability modelling using GIS, Lantana Island, Hong Kong', Geomorphology 42, 213-228. http://dx.doi. org/10.1016/S0169-555X(01)00087-3

Diko, M.L., 2012, 'Community engagement in landslide risk assessment in Limbe, Southwest Cameroon', Scientific Research and Essays 7(32), 2906-2912.

Diko, M.L., Ekosse, G.E., Ayonghe, S.N. \& Ntasin, E., 2011, 'Physical characterization of clayey materials from Tertiary volcanic cones in Limbe (Cameroon) for ceramic applications', Applied Clay Science 51, 380-384. http://dx.doi.org/10.1016/j. clay.2010.11.034

Diko, M.L., Ekosse, G.E., Ayonghe, S.N. \& Ntasin, E., 2012, 'Physical and geotechnical characterization of unconsolidated sediments associated with the 2005 Mbonjo landslide, Limbe, Cameroon', International Journal of Physical Sciences 7(20), 27842790.

Ekosse, G.E., Ngole, V., Sendze, Y. \& Ayonghe, S.N., 2005, 'Environmental mineralogy of unconsolidated surface sediments associated with the 2001 landslides on volcanic cones, Mabeta New Layout, Limbe, Cameroon', Global Journal of Environmental Studies 4(2), 115-122.

Ercanoglu, M. \& Gokceoglu, C., 2002, 'Assessment of landslide susceptibility for a landslide-prone area (north of Yenice, NW Turkey) by Fuzzy approach', Environmental Geology 41, 720-730. http://dx.doi.org/10.1007/s00254-001-0454-2

Ercanoglu, M., Gokceoglu, C. \& Van Aseh, W., 2004, 'Landslide susceptibility zoning north of Yenice (NW Turkey) by multivariate statistical techniques', Natural Hazards 32, 1-32. http://dx.doi.org/10.1023/B:NHAZ.0000026786.85589.4a

Fall, M. \& Sarr, M.A., 2007, 'Geotechnical characterization of expansive soils and their implications in ground movements in Dakar', Bulletin of Engineering Geology and Environment 66, 279-288. http://dx.doi.org/10.1007/s10064-006-0070-1

Guzzetti, F., Cardinali, M. \& Reichenbach, P., 1999, 'Landslide hazard evaluation: A review of current techniques and their application in multi-scale study, central Italy', Geomorphology 31, 181-216. http://dx.doi.org/10.1016/S0169-555X(99)00078-1

Knapen, A., Kitutu, M.G., Poesen, J., Bregelmans, W., Deckers, J. \& Muwanga, A., 2006, 'Landslides in densely populated county at the footslopes of Mount Elgon (Uganda): Characteristics and Casual Factors', Geomorphology 73, 149-165. http://dx.doi. org/10.1016/j.geomorph.2005.07.004

Lee, E.M. \& Zones, D.K.C., 2004, Landslide risk assessment, Thomas Telford, London. http://dx.doi.org/10.1680//ra.31715

Micheal-Leiba, M., Baynes, F., Scott, G. \& Granger, K., 2003, 'Regional landslide risk to the Cairns community', Natural Hazards 32, 233-249. http://dx.doi. org/10.1023/A:1026122518661

Mugagga, F., Kakembo, V. \& Buyinza, M., 2011, 'A characterisation of the physical properties of soil and the implications for landslide occurrence on the slopes of Mount Elgon, Eastern Uganda', Natural Hazards 60(3), 1113-1131. http://dx.doi. org/10.1007/s11069-011-9896-3

Ngole, V.M., Ekosse, G. \& Ayonghe, S.N., 2007, 'Physico-chemical, mineralogical and chemical considerations in understanding the 2001 Mabeta New Layout landslide, Cameroon', Journal of Applied Science and Environmental Management 11(2), 201-208.

Pachauri, A.K. \& Pant, M., 1992, 'Landslide hazard mapping based on geological attributes', Engineering Geology 50, 71-74.

Pachauri, A.K., Gupta, P.V. \& Chandler, R., 1998, 'Landslide zoning in part of the Garhwal Himalayas', Environmental Geology 36, 325-334. http://dx.doi.org/10.1007/ s002540050348

Parker, A. \& Rae, J.E. (eds.), 1998, Environmental interactions of clays, Springer, New York. http://dx.doi.org/10.1007/978-3-662-03651-8

Plummer, C.C., Geary, D.M. \& Carlson, P.H., 1999, Physical geology, McGraw Hill Co., New York.

Singh, R.G., Botha, G.A., Richards, N.P. \& McCarthy, T.S., 2008, 'Holocene landslides in Kwazulu-Natal, South Africa', South African Journal of Geology 111(1), 39-52. http://dx.doi.org/10.2113/gssajg.111.1.39

Summa, V., Tateo, F., Giannossi, M.L. \& Bonelli, C.G., 2010, 'Influence of clay mineralogy on the stability of a landslide in Plio-Pleistocene clay sediments near Grassano (Southern Italy)', Catena 80, 75-85. http://dx.doi.org/10.1016/j.catena.2009.09.002

Talerico, J., Schuring, J.R. \& Khera, R.P., 2004, 'A landslide in glacial soils of New Jersey', paper presented at the 5th International Conference on Case Histories in Geotechnical Engineering, New York, 13-17 April.

Van Western, C.J., Rengers, N., Terlien, M.T. \& Soeters, R., 1997, 'Prediction of the occurrence of slope instability phenomena through GIS-based hazard zonation' Geology Rundsch 86, 404-414. http://dx.doi.org/10.1007/s005310050149

Varnes, D.J., 1984, Landslide hazard zonation: A review of principles and practice, UNESCO, Paris.

Yalcin, A., 2007, 'The effects of a landslide: A case study', Applied Clay Science 38, 77-85. http://dx.doi.org/10.1016/j.clay.2007.01.007

Zezere, J.L., Ferrira, A.B. \& Rodrigue, M.L., 1999, 'Landslides in the north of Lisbon (Portugal): Conditioning and triggering factors', Physics and Chemistry of the Earth 24(10), 925-934. http://dx.doi.org/10.1016/S1464-1895(99)00137-4 